\title{
Abrasividade pendular e a resistência mecânica das rochas
}

\author{
Gouging abrasion and the mechanical \\ strength of rocks
}

\begin{abstract}
Vilmondes Ribeiro
Engenheiro Elétrico, IPT - Instituto de Pesquisas Tecnológicas do Estado de São Paulo S.A. vilmonds@ipt.br
\end{abstract}

\section{Lineu Azuaga Ayres da Silva \\ Professor Titular do Departamento \\ de Engenharia de Minas e de Petróleo \\ Escola Politécnica da Universidade de São Paulo. \\ layres@usp.br}

\section{Eduardo Cesar Sansone}

Professor Dr. do Departamento de

Engenharia de Minas e de Petróleo

Escola Politécnica da Universidade de São Paulo. esansone@usp.br

\section{Resumo}

Esse trabalho emprega o método para avaliar a abrasividade proposto por Golovanevskiy e Bearman (2008). Esse método, ensaio de abrasão por impacto deslizante (Gouging Abrasion Test), é realizado em condições de alta tensão/alto impacto de desgaste. O método consiste de uma ponteira cilíndrica com uma ponta cônica de $90^{\circ}$, que, em trajetória pendular, atinge uma amostra de rocha com energia de impacto de $300 \mathrm{~J}$ e velocidade da ordem de 5,2 m/s. O Gouging Abrasion Index (Gi) é calculado como sendo a média do diâmetro da ponta cônica, após desgaste, em milímetros e o resultado é multiplicado por 10. Esse trabalho verificou a adequabilidade do Gouging Abrasion Test, para um pequeno número de amostras de rocha, que representam, qualitativamente, os principais tipos de rocha encontrados em trabalhos de corte, perfuração e britagem no Brasil, e a sua correlação com outros ensaios consagrados como a resistência à compressão, o desgaste Amsler e a dureza Knoop. Essa análise mostrou alta correlação entre Gi e a dureza Knoop $\left(\mathrm{R}^{2}=0,94\right)$, baixa correlação com o desgaste Amsler $\left(\mathrm{R}^{2}=0,41\right)$ e nenhuma correlação com resistência à compressão uniaxial.

Palavras-chave: Mecânica de rochas, abrasão, esclerometria pendular.

\begin{abstract}
This paper employs the method for evaluating abrasion proposed by Golovanevskiy e Bearman (2008). This method, Gouging Abrasion Test, employs high-stress load gouging/sliding impact wear. The method consists of a steel wear tool with a $90^{\circ}$ sharp conical tip. This tip attacks a rock sample in a swinging trajectory with an impact energy of $300 \mathrm{~J}$ and a speed of around $5.2 \mathrm{~m} / \mathrm{s}$. The Gouging Abrasion Index (Gi) is determined as 10 times the average diameter in millimeters of the conical tip (now flat) after one event of wear. This paper evaluates the Gouging Abrasion Test suitability in a small group of rocks that represents some of the main types to be found in Brazil's rock cutting, drilling and crushing works. Its relationship to other usual tests like uniaxial compressive strength, Amsler abrasive wear and Knoop hardness were also verified. The results show high correlation between Gi and Knoop hardness $\left(R^{2}=0,94\right)$, low correlation with Amlser wear $\left(R^{2}=0,41\right)$ and no relation to uniaxial compressive strength.
\end{abstract}

Keywords: Rock Mechanics, abrasion, gouging abrasion. 


\section{Introdução}

O desgaste de ferramentas é um problema de grande importância em vários campos da engenharia civil e de minas, envolvendo implicações econômicas, pois há casos em que uma inesperada alta taxa de desgaste das ferramentas de corte e uma baixa produção resultaram em elevadas perdas financeiras e litígio entre empreiteiros, consultores e clientes (Deketh, 1995).

Deve-se estar atento às várias e diferentes aplicações técnicas nos campos da engenharia civil e mineração: perfuração de rocha, escavação de rocha por máquinas (TBM's e fresadoras), corte e lavra de rochas em minas e pedreiras, cominuição de rocha por britadores e moinhos e outras. Frequentemente para uma determinada aplicação, corresponde um particular funcionamento do instrumento ou

\section{Materiais e métodos}

Uma amostra de rocha plana retangular é colocada em um porta-amostra. Uma ponteira de aço, com a ponta cônica, é afixada ao braço de um pêndulo em balanço e o arco da viagem do pêndulo é ajustado de modo que a ponteira, forçosamente, entre em contato com a superfície da amostra da rocha. Esse contato deve ocorrer na região de maior energia cinética do curso do pêndulo e em uma única passada.

O esquema do aparelho de ensaio

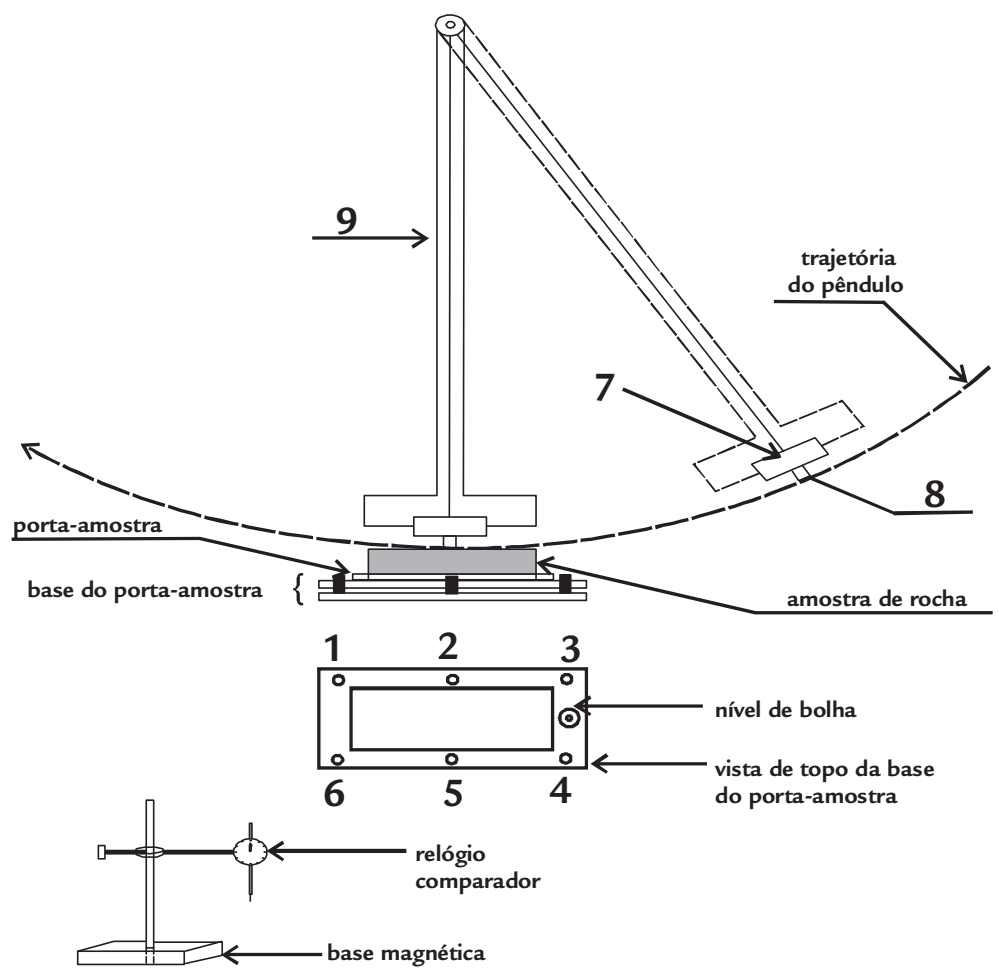

da máquina, de modo que os parâmetros envolvidos no fenômeno podem ser diferentes de um caso para outro (Innaurato; Mancini, 1996).

A abrasividade é uma propriedade que reflete o efeito da perda de volume que rochas e minerais provocam, no contato com outros materiais, e, portanto, tem uma grande influência sobre a vida útil e a eficiência dos equipamentos que manuseiam esses materiais. Há vários métodos para estimar a abrasividade de rochas e minerais, empregados com diferentes graus de sucesso e relevância e, dentro desse contexto, o ensaio de abrasão por impacto deslizante (Gouging Abrasion Test), objeto desse trabalho, proposto por Golovanevskiy e Bearman (2008), é realizado em condições de alta ten-

de abrasão Gouging é mostrado na Figura 1 . O equipamento nada mais é do que o pêndulo para ensaio de impacto Charpy modificado. Aqui, a amostra de rocha é fixada de forma segura no porta-amostra. O porta-amostra pode ser movido verticalmente com o auxílio de parafusos (1, 3, 4 e 6). Isto é possível porque a base do porta-amostra é composta de duas placas metálicas superpostas (Figura 2), de modo que a placa superior desloca-se, em relação à placa inferior com o auxílio são/alto impacto de desgaste e é caracterizado pela maior taxa de remoção de material de todos os modos de desgaste e, portanto, representa o modo mais severo de desgaste abrasivo.

Esse estudo tem, como objetivo, avaliar se o Gouging Abrasion Test apresenta resultados coerentes com outras metodologias, quando aplicado a um pequeno número de amostras de rochas, mas que representam, qualitativamente, os principais tipos de rochas encontrados no Brasil (com resistência à compressão uniaxial variando entre 100 e $250 \mathrm{MPa}$ ). Portanto essas amostras foram ensaiadas, segundo esse método e, a partir daí, foi verificada a sua correlação com outros ensaios consagrados, como a resistência à compressão, o desgaste Amsler e a dureza Knoop.

dos parafusos já mencionados. O portaamostra pode ser fixado em sua base, em duas posições diferentes, o que permite dois ensaios para cada corpo-de-prova (Figura 3). Uma ponteira (8) é rigidamente posicionada no porta-ponteira (7) do braço do pêndulo (9). O braço do pêndulo é liberado de sua posição de trabalho e, assim, a ponta da ponteira é aplicada à superfície da amostra de rocha na descida do pêndulo. A energia de impacto total disponível é de, aproximadamente,
Figura 1

Diagrama do aparelho de ensaio abrasivo por impacto deslizante. 
$300 \mathrm{~J}$ e a velocidade de impacto é da ordem de $5,2 \mathrm{~m} / \mathrm{s}$.

A Figura 4 mostra o aparelho de ensaio utilizado (marca: Web-Werkstoffprüfmaschine).

No ensaio Gouging, grande ênfase é dada às dimensões e à qualidade da superfície de desgaste do corpo-de-prova. Assim, cada corpo-de-prova, com dimensão final de 100 x $30 \times 11 \mathrm{~mm}(\mathrm{C}$ x $\mathrm{L} \times \mathrm{E}$ ), foi preparado, inicialmente, com serra diamantada. Após essa etapa, a base e o topo, do corpo-de-prova, foram desgastados mediante torno com rebolo diamantado, para garantir paralelismo entre ambos, bem como para excluir a influência da rugosidade da superfície no resultado dos ensaios. Isto está ilustrado na Figura 5.

Após cada uma das duas etapas, citadas no parágrafo anterior, o corpode-prova deve ser inspecionado quanto a defeitos inerentes ou defeitos induzidos, pelo corte ou desgaste, e descartado caso seja considerado impróprio para o teste.

Figura 2

Base do porta-amostra.

Figura 3

Base do porta-amostra destacando as duas possibilidades de fixação.

Figura 4

Aparelho de ensaio abrasivo por impacto deslizante.

Figura 5

Aparência de corpo-de-prova

para ensaio.
Se considerado satisfatório, o corpo-deprova deve, então, ser seco por $3 \mathrm{~h} \mathrm{em}$ uma estufa a $60^{\circ} \mathrm{C}$ ou por $24 \mathrm{~h}$, em temperatura ambiente.

A dureza da ponteira de desgaste deve ser tal que garanta uma medida confiável da remoção de material, sofrida por esta ferramenta, durante o teste de abrasão Gouging, para uma ampla faixa de rochas e minerais. Ela não pode ser muito alta ou muito baixa, pois isto poderia levar a um insuficiente ou excessivo desgaste da ferramenta. Nesse contexto, o nível de dureza Rockwell de 40/42 HRC foi selecionado como o adequado para testar uma série de rochas, cobrindo uma boa faixa de abrasividade (Golovanevskiy; Bearman, 2008).

As ponteiras têm, em uma de suas extremidades, um perfil cônico de $90^{\circ}$, terminando em uma seção de $9 \mathrm{~mm}$ de diâmetro. A outra extremidade tem diâmetro de 5,6 mm, sendo este o lado que é encaixado no porta-ponteiras. O comprimento total é de $19 \mathrm{~mm}$ (Figura 6).
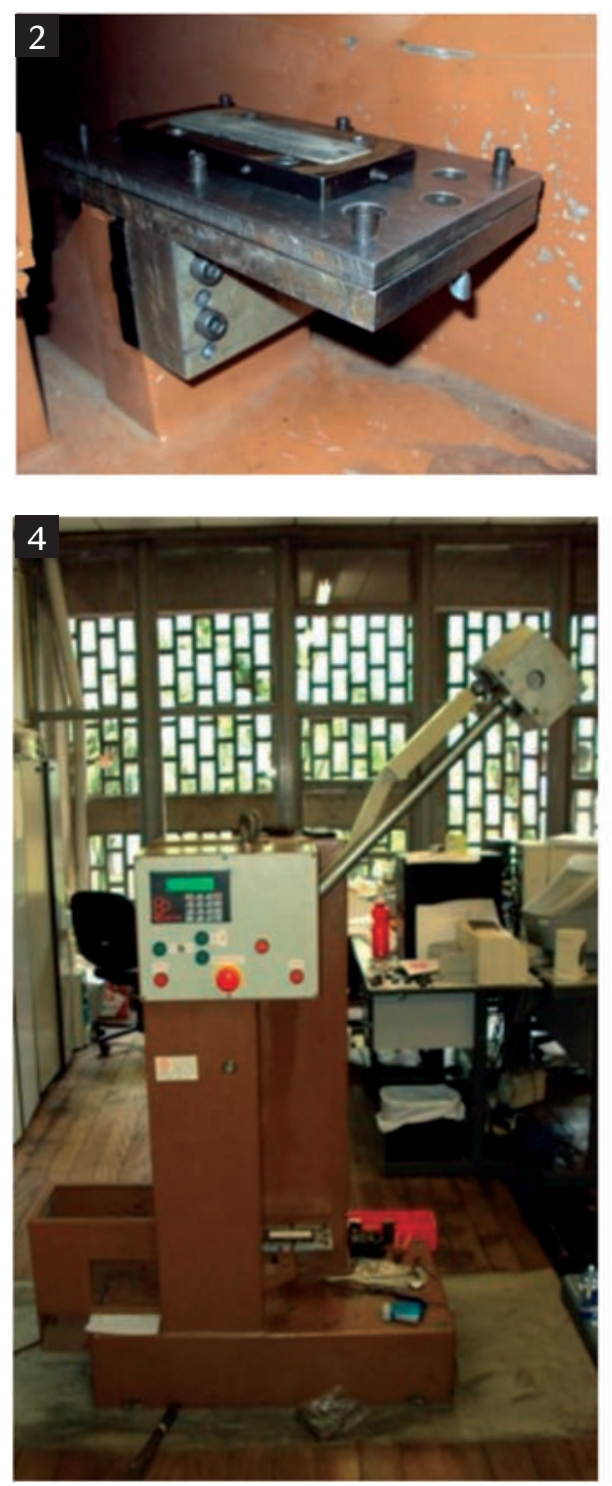

Os corpos-de-prova, preparados como descrito anteriormente, são montados no porta-amostra do aparelho de ensaio e presos de modo a impedir qualquer possibilidade de movimento durante o ensaio. Especial ênfase é dada para garantir que a superfície de desgaste da amostra de rocha esteja bem nivelada. Para permitir ajuste e facilidade de utilização, o porta-amostra, como já descrito anteriormente, pode ser movido na vertical (de forma contínua) e na horizontal (duas posições).

A ponteira deve ser encaixada no porta-ponteira do braço do pêndulo, de modo a garantir que, quando o braço estiver totalmente suspenso (posição vertical), a ponta cônica deve apontar, verticalmente, para o corpo-de-prova. Nesse ponto, há um leve contato entre a superfície do corpo-de-prova e a ponta cônica da ponteira, que é, então, firmemente fixada no porta-ponteira, por meio de parafuso (Figura 7).

Em seguida, o braço do pêndulo é
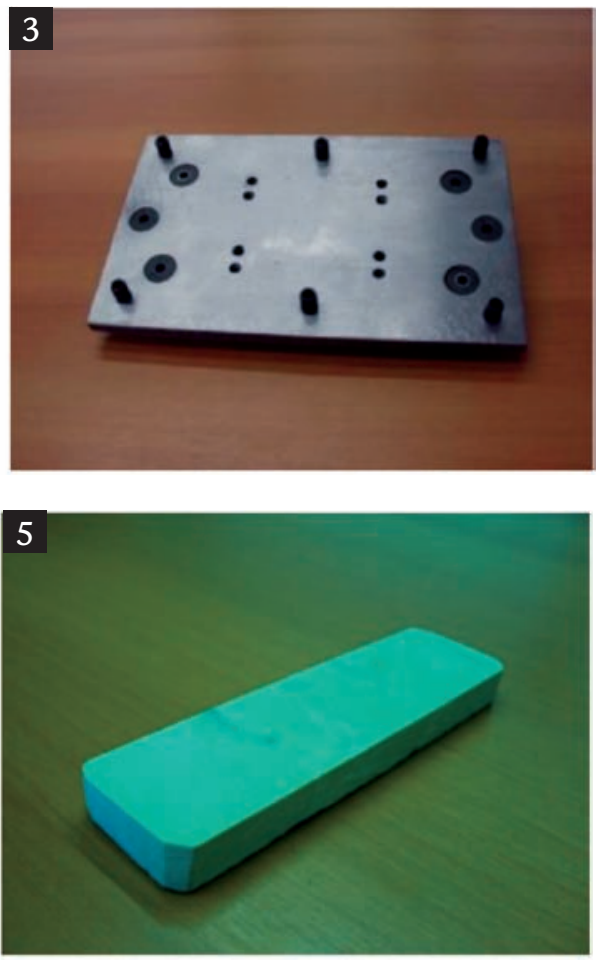
levantado até sua posição inicial (aproximadamente $160^{\circ}$ em relação à vertical). Um micrômetro fixado, em uma base magnética (ver Figuras 8 e 9), é posicionado, de modo a medir um deslocamento vertical ascendente (realizado como já descrito), da base do porta-amostra de 1 $\mathrm{mm}$. Isto garante $1,0 \mathrm{~mm}$ de profundidade, disponível entre o contato da ferramenta de desgaste e o corpo-de-prova. Para garantir que a superfície do portaamostra esteja bem nivelada, um nível de bolha (tipo olho de boi) foi utilizado.

O pêndulo é, então, liberado. A ponta cônica faz uma fenda na amostra de rocha, na trajetória de descida do pêndulo. O pêndulo continua sua trajetória, após passar pela amostra de rocha, até parar, quando então é travado. Após o travamento do pêndulo, retira-se a ponteira para inspeção e medida de desgaste. Em seguida, o porta-amostra é sacado de sua posição inicial e deslocado, lateralmente, para sua segunda posição de
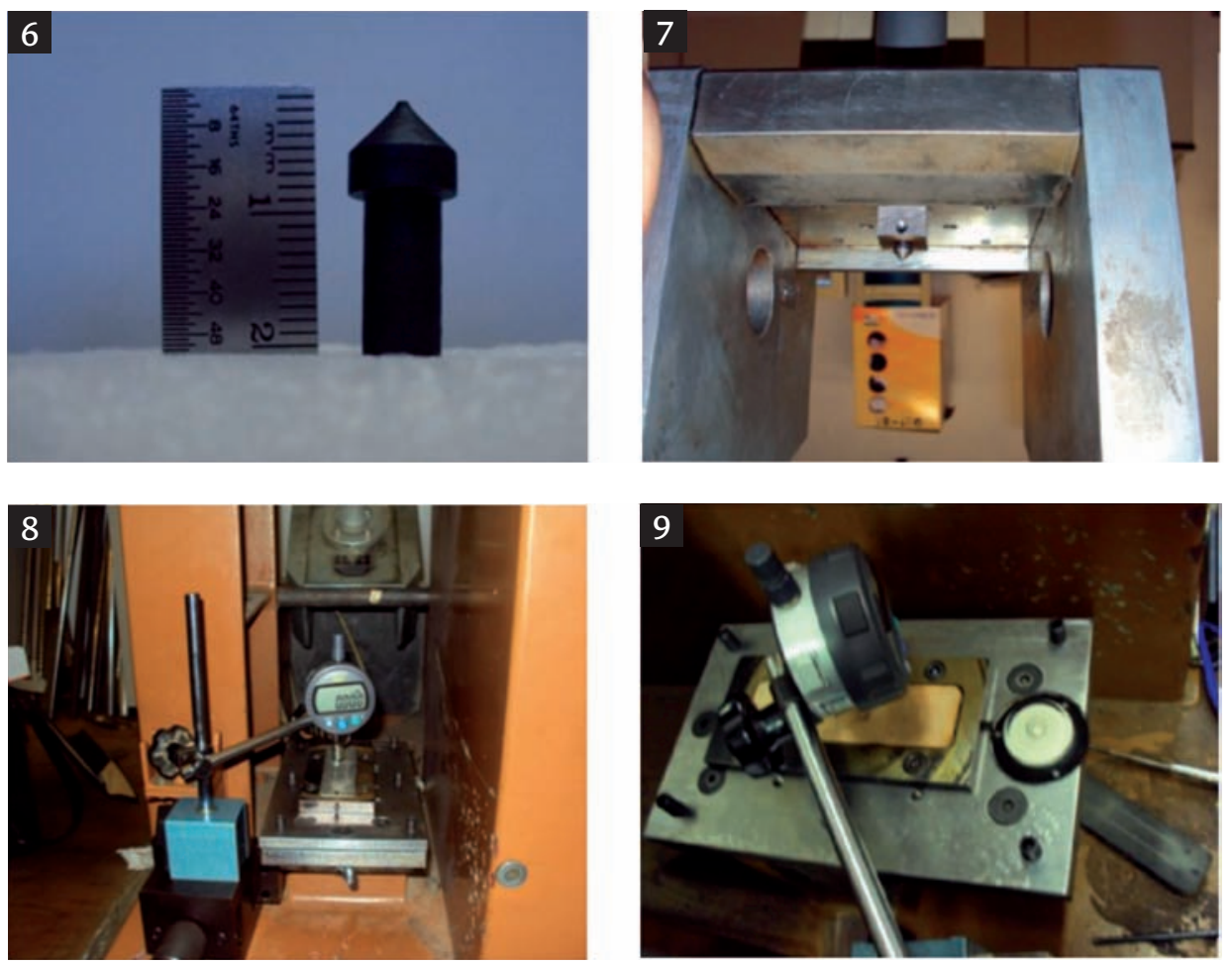

fixação no porta-amostra $(10 \mathrm{~mm}$ disponto, repete-se a operação até aqui descrita, para permitir um novo desgaste na superfície da amostra em uma próxima passagem do pêndulo. Portanto o procedimento assim descrito constitui-se de um teste com uma única passada. Para cada passagem subsequente, uma nova ponta é colocada no braço do pêndulo e repete-se o procedimento. A Figura 10 mostra uma seleção de amostras de rochas, após o teste.

Semelhante à metodologia de cálculo de abrasividade das rochas relatado por West (1989), para o teste Cerchar, o Gouging Abrasion Index (Gi) é calculado como sendo a média do diâmetro da ponta cônica, após desgaste, em milímetros, multiplicada por 10 e é determinado como se segue.

Após o teste, a ponta cônica da ferramenta de desgaste é limpa de quaisquer detritos de rocha e a sua face de desgaste
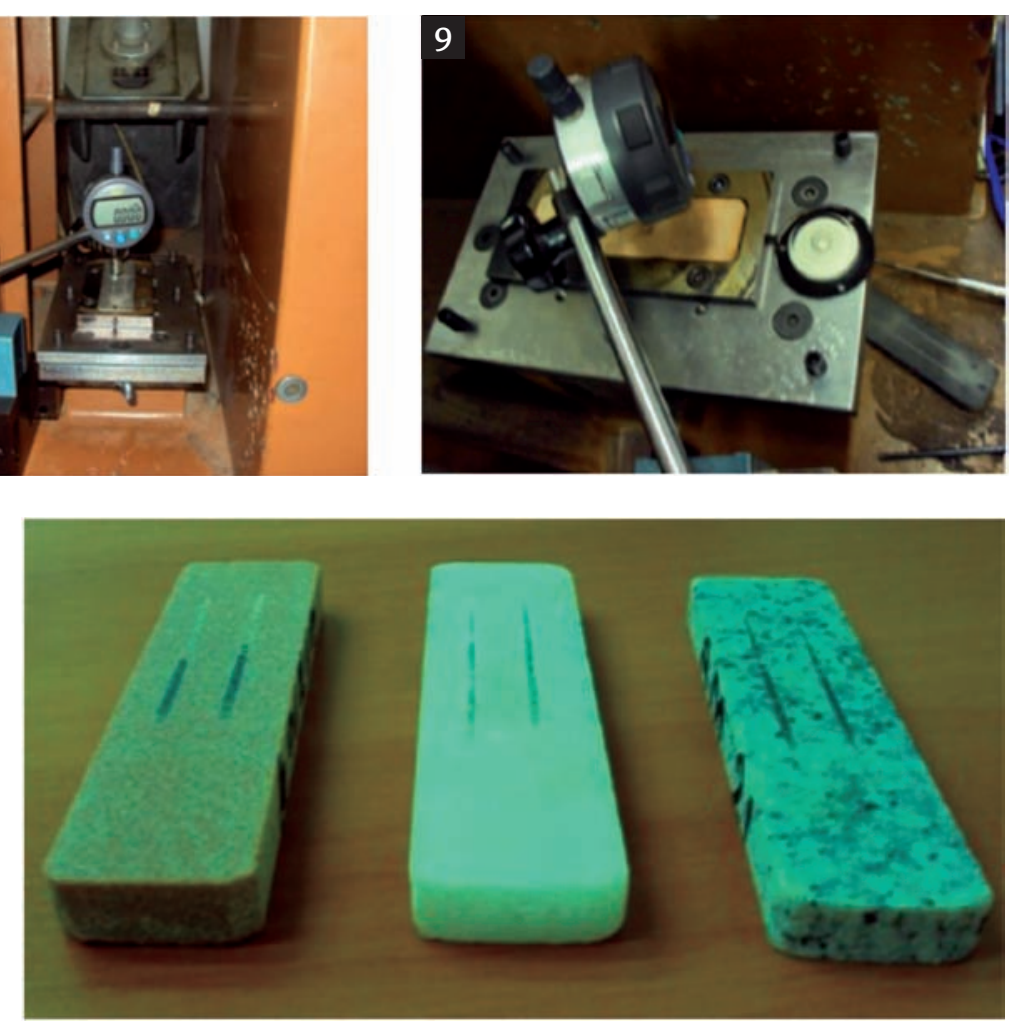

é examinada, visualmente, com um estereomicroscópio com ampliação de 4 vezes, ou maior ampliação, para avaliar sua adequação para a medida dos diâmetros. Se a face de desgaste parecer ser irregular, com ranhuras, e, geralmente, tendo uma superfície não uniforme, a ferramenta é considerada imprópria para medida dos diâmetros e, portanto, o correspondente teste feito por essa ponta é considerado perdido.

Quando a face de desgaste encontrada for plana e, portanto, adequada para medições, as medidas de diâmetro são feitas com a utilização de um estereomicroscópio com aplicação de 20 vezes, ou superior ampliação, equipado com micrômetro graduado em $0,001 \mathrm{~mm}$ ou sistema digital de medidas com igual ou superior resolução. Como a face desgastada pode gerar uma área que não tenha o mesmo diâmetro em toda superfície, são feitas duas medidas de diâmetro, para cada ponta, que são tomadas em di-

Figura 6

Ponteira de desgaste.

Figura 7

Ponteira de desgaste

fixada no porta-ponteira.

Figura 8

Micrômetro fixado na base da máquina de ensaio para permitir a leitura de $1 \mathrm{~mm}$ de deslocamento vertical.

Figura 9

Base do porta-amostra de rocha com nível de bolha.

Figura 10

Aspecto das amostras de rochas após ensaio. 
reções ortogonais. A média, dessas duas leituras, é relatada como o diâmetro da superfície da ponta cônica após desgaste em milímetros. As projeções dos perfis de uma ponta adequada para medidas e de outra inadequada para medidas são mostradas nas Figuras 11 e 12, respectivamente.

Projeções das faces de uma ponta adequada para medidas e de outra inade-

Figura 11

Ponteira com perfil adequado para leitura de diâmetros. Lupa Nikon (x30).

Figura 12

Ponteira com perfil inadequado para leitura de diâmetros. Lupa Nikon (x30).

Figura 13

Face adequada para medida de diâmetros (Microscópio Olympus BX60M).

Figura 14 Face inadequada para medida de diâmetros (Microscópio Olympus

BX60M).

\section{Resultados}

Para esse estudo, foi selecionado um pequeno número de amostras de rocha que representam, qualitativamente, os principais tipos de rochas encontradas no Brasil com resistência à compressão uniaxial entre 100 e $250 \mathrm{MPa}$.

As rochas selecionadas foram:

Bege Bahia (rocha sedimentar): Calcário. Predomínio de calcita com alguma dolomita com quantidades variáveis de quartzo e calcedônia. É extraído no município de Ourolândia, BA.

- Classificação Petrográfica: Calcário Micrítico.

- Caracterização Tecnológica: a) Compressão Uniaxial (MPa) 154,2; b) Desgaste Amsler (mm/1000m) 2,18;

c) Dureza Knoop (Gpa) 1,870; d) Gouging Abrasion Index (Gi) 13,02.

Mármore Branco Mantiqueira (rocha metamórfica): Mármore dolomítico constituído por cerca de $90 \%$ de dolomita e $7 \%$ de calcita com a sílica sob a quada para medidas podem ser vistas nas Figuras 13 e 14, respectivamente.

Para que se obtenha um valor representativo de Gi, uma série de testes deve ser realizada em uma única amostra de rocha. Porém, "na prática", um mínimo de três passagens de teste deve ser feito em uma única amostra de rocha, cada uma usando uma nova ferramenta de desgaste e uma nova superfície a ser
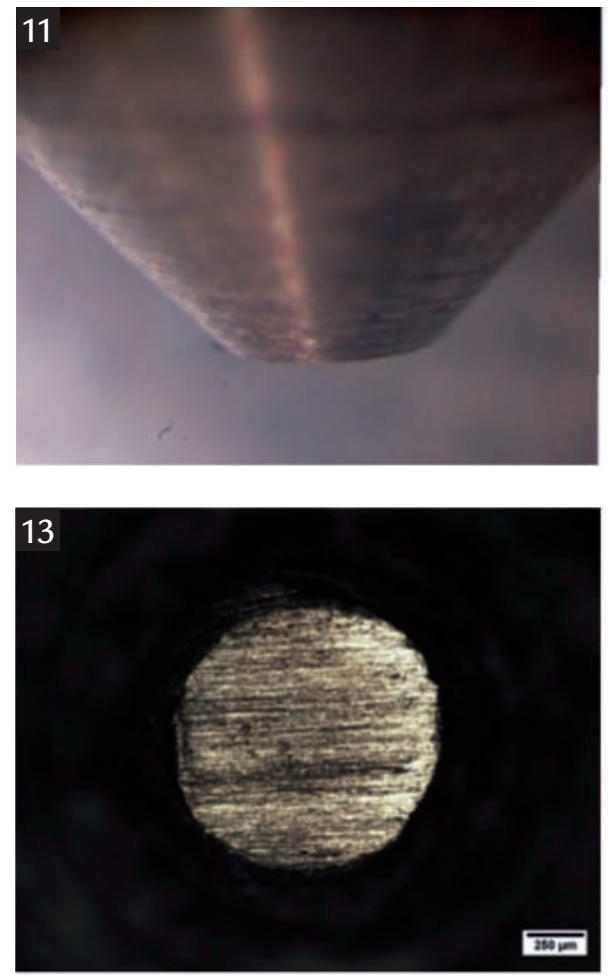

forma de silicatos, tais como olivina, tremolita, serpentinita e talco. Ocorre no município de Campos do Jordão, SP.

- Classificação Petrográfica: Calcita Dolomita Mármore.

- Caracterização Tecnológica: a) Compressão Uniaxial (MPa) 108,5; b) Desgaste Amsler (mm/1000m) 4,42; c) Dureza Knoop (GPa) 2,982; d) Gouging Abrasion Index (Gi) 15,46.

Arenito (rocha sedimentar): Rocha presente na região central do Estado de São Paulo nas Formações Botucatu e Pirambóia, da bacia do Paraná. Possui origem eólica. São constituídos, praticamente, por $100 \%$ de grãos finos e arredondados de quartzo.

- Classificação Petrográfica: Quartzo Arenito.

- Caracterização Tecnológica: a) Compressão Uniaxial (MPa) 131,5 paralelo / 192,8 ortogonal; b) Desgaste Amsler (mm/1000m) 1,25; c) Dureza

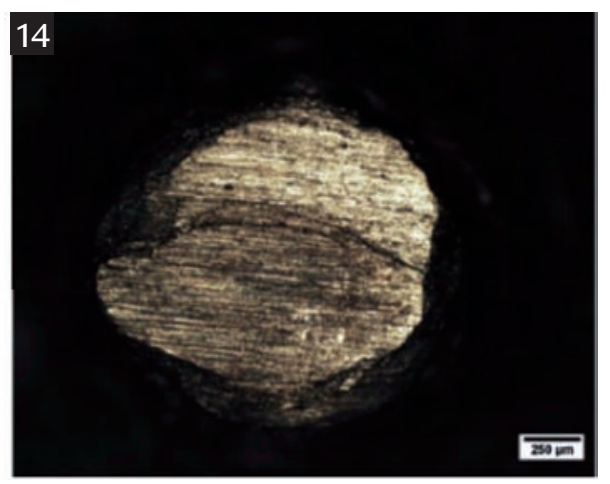

desgastada. Isto pode ser feito com três ponteiras e uma amostra de rocha de 25 a $30 \mathrm{~mm}$ de largura (Golovanevskiy e Bearman, 2008).

Nesse trabalho, optou-se por duas passagens de teste para cada corpo-deprova, sendo que a amostra de rocha é considerada avaliada com no mínimo 4 ponteiras com leituras e diâmetros considerados válidos.

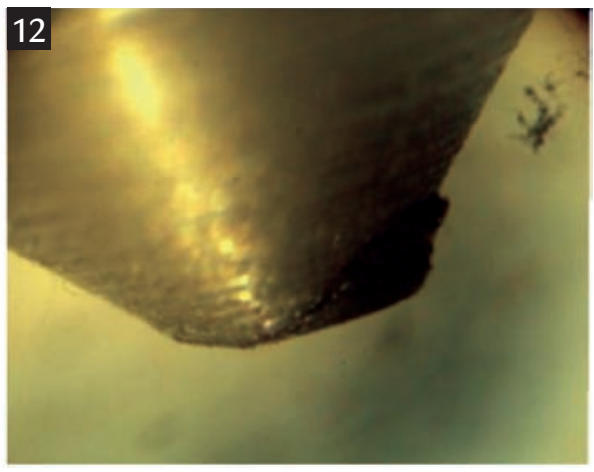

Knoop (GPa) 11,070; Gouging Abrasion Index (Gi) 20,17.

Basalto (rocha ígnea): Rocha formada a partir dos extensos derrames vulcânicos cretáceos na bacia do Paraná que ocorreram nos Estados de SP, PR, MS, GO, SC, RS e MG. A amostra é procedente do MS.

- Classificação Petrográfica: Basalto

- Caracterização Tecnológica: a) Compressão Uniaxial (MPa) 229,9; b) Desgaste Amsler (mm/1000m) 1,24; c) Dureza Knoop (Gpa) 4,340; d) Gouging Abrasion Index (Gi) 16,44.

Diabásio (rocha ígnea): Rocha extraída no município de Taió, SC e ocorre como intrusões concordantes (sills) e por vezes discordantes (diques) do magma correlato à Formação Serra Geral nos sedimendomina labradorita (50\%). Augita opaca (piroxênio) (30\%), magnetita e ilmenita tos mais antigos da bacia do Paraná. Pre- 
(15\%) e até $5 \%$ de quartzo.

- Classificação Petrográfica: Diabásio.

- Caracterização Tecnológica: a) Comte Amsler (mm/1000m) 0,52; c) Dureza Knoop (GPa) 5,990; d) Gouging Abrasion Index (Gi) 17,05.

Granito Cinza Mauá (rocha ígnea): Rocha do município de Suzano, SP. Biotita monzogranito porfirítico. Apresenta matriz fina com fenocristais de até $2 \mathrm{~cm}$. Microclínio (35\%), plagioclásio (30\%), quartzo $(30 \%)$ e biotita (15\%).

- Classificação Petrográfica: Biotita Monzogranito Porfirítico.

- Caracterização Tecnológica: a) Compressão Uniaxial (MPa) 147,3; b) Desgaste Amsler (mm/1000m) 0,76; c) Dureza Knoop (Gpa) 7,146; Gouging Abrasion Index (Gi) 18,60. pressão Uniaxial (MPa) 243; Desgas-
Granito Vermelho Capão Bonito (rocha ígnea): Rocha do município de $\mathrm{Ca}-$ Possui granulação média, homogênea e é composto, principalmente, por microclínio (35\%), quartzo (30\%), plagioclásio $(25 \%)$ e biotita $(10 \%)$.

- Classificação Petrográfica: Biotita Monzogranito.

- Caracterização Tecnológica: a) Compressão Uniaxial (MPa) 149,8; b) Desgaste Amsler (mm/1000m) 0,60; c) Dureza Knoop (GPa) 7,926; d) Gouging Abrasion Index (Gi) 17,98

Após a execução dos ensaios para a obtenção dos valores de Gi, para as rochas selecionadas, foi possível verificar o grau de correlação entre esse parâmetro e os demais propostos, quais sejam, resistência à compressão uniaxial, desgaste Amsler e dureza Knoop.

A partir desses dados, obtiverampão Bonito, SP. Biotita monzogranito.

se os seguintes valores de coeficiente de determinação:

- Resistência à Compressão Uniaxial e Gouging Abrasion Index de 0,1351 (Figura 15).

- Desgaste Amsler e Gouging Abrasion Index de 0,4122 (Figura 16).

- Dureza Knoop e Gouging Abrasion Index de 0,9464 (Figura 17).

$\mathrm{Na}$ análise de regressão, foi utilizado o software Minitab® versão 16. Nessa análise, não se verificou equação de regressão que tivesse ajuste significativo (p-valor < 0,05) para CU x Gi e Amsler x Gi, ao passo que Knoop x Gi, tanto a linear ( $\mathrm{p}$-valor $=0,001, \mathrm{R}^{2}=0,9010 \mathrm{e}$ $\mathrm{R}^{2}$-adj $\left.=0,8812\right)$, quanto a quadrativa $\left(\mathrm{p}\right.$-valor $=0,022, \mathrm{R}^{2}=0,9464$ e $\mathrm{R}^{2}$-adj $=0,9197)$, foram consideradas significativas. Nesse caso, optou-se pela equação quadrática por apresentar $\mathrm{R}^{2}$-adj ligeiramente maior.

\begin{tabular}{c|c|c}
\hline $\begin{array}{c}\text { Compressão } \\
\text { Uniaxial }\end{array}$ & GI & Rocha \\
\hline 154,2 & 13,02 & Bege Bahia \\
\hline 108,5 & 15,46 & B. Mantiqueira \\
\hline 149,8 & 17,98 & Capão Bonito \\
\hline 192,8 & 19,92 & Arenito \\
\hline 243,0 & 17,05 & Gabro \\
\hline 229,9 & 16,44 & Basalto \\
\hline 147,3 & 18,60 & Cinza Maua \\
\hline \multicolumn{3}{|l}{} \\
0
\end{tabular}

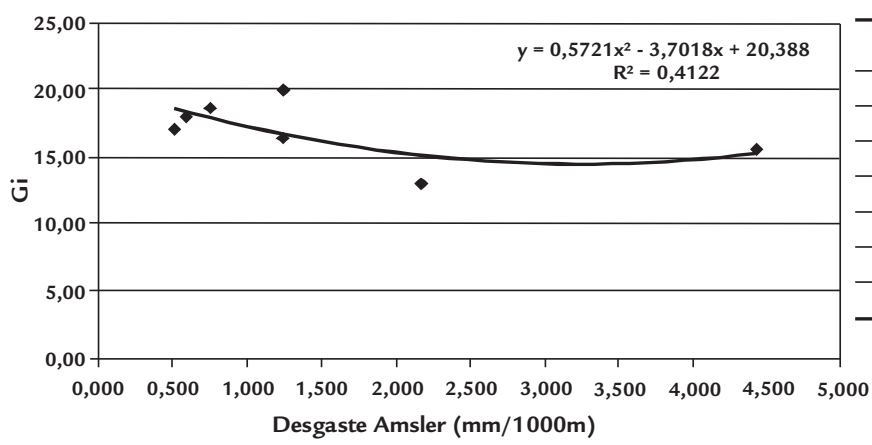

\begin{tabular}{c|c|c}
\hline $\begin{array}{c}\text { Desgaste } \\
\text { Amsler }\end{array}$ & GI & Rocha \\
\hline 2,180 & 13,02 & Bege Bahia \\
\hline 4,420 & 15,46 & B. Mantiqueira \\
\hline 0,600 & 17,98 & Capão Bonito \\
\hline 1,250 & 19,92 & Arenito \\
\hline 0,520 & 17,05 & Gabro \\
\hline 1,240 & 16,44 & Basalto \\
\hline 0,760 & 18,60 & Cinza Maua \\
\hline \multicolumn{4}{|c}{} \\
0
\end{tabular}

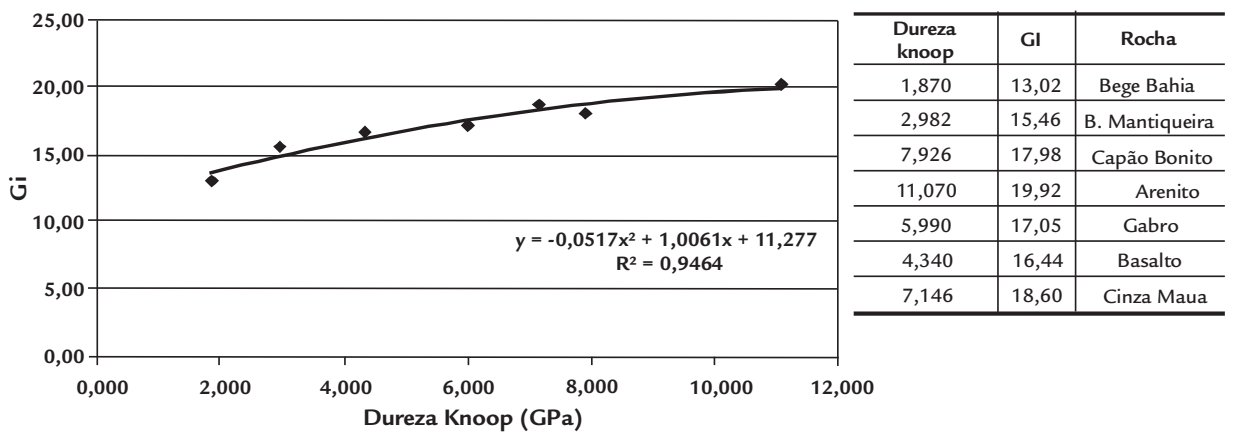

\section{Discussão e conclusão}

Esse estudo teve como principal objetivo avaliar se o Gouging Abrasion Test apresenta resultados coerentes com outras metodologias, especialmente, o desgaste Amsler e a dureza Knoop. Nesse sentido, observa-se que o desgaste
Figura 15

Valores de compressão uniaxial x Gi.

Figura 16

Valores desgaste Amsler x Gi.

Figura 17

Valores de dureza Knoop x Gi.

Amsler é um ensaio dinâmico, que verifica o desgaste à abrasão (por atrito), em uma superfície de rocha, utilizando-se 
de um agente intermediário (areia). Assim, é influenciado pela mineralogia e textura (granulação, arranjo mineral) da amostra. Já a dureza Knoop é um ensaio quase-estático, onde se tem a medida em um número de pontos (40) significativos e que, portanto, ao final, irá fornecer um parâmetro representativo da influência das características mineralógicas, texturais e estruturais.

O Gouging Abrasion Index (Gi), por sua vez, é um ensaio dinâmico em que uma ponteira de metal impacta e atrita contra a rocha, com alta energia. O resultado do ensaio é, fortemente, condicionado pelas características mineralógicas, texturais e estruturais da rocha. Pelas correlações de segundo grau encontradas $\left(\mathrm{R}^{2}\right.$ de CU x Gi de 0,1351, R ${ }^{2}$ de Amsler x Gi de 0,4122 e R ${ }^{2}$ de Knoop x Gi de 0,9464), e tendo em vista a natureza dos ensaios estudados, pode-se inferir que os métodos Knoop e Gi, verificam as mesmas propriedades dos materiais estu- dados. Embora Gi seja, essencialmente, dinâmico e o Knoop, quase-estático, ambos fornecem resultados influenciados fortemente pelos aspectos mineralógicos, texturais e estruturais das rochas ensaiadas. Daí ser bastante consistente a correlação entre os resultados obtidos sobre as mesmas amostras de rochas para ambos. Deve-se lembrar também que o volume percentual de quartzo, nas amostras, foi um forte condicionante de desgaste da ponteira.

\section{Referências}

DEKETH, H.J.R. Wear of rock cutting tools: laboratory experiments on the abrasivity of rock. Rotterdam: A.A.Abalkema, 1995. 143p.

FRASCÁ, M.H.B.de O. (Coord.). Rochas ornamentais e de revestimento do Estado de São Paulo. São Paulo: IPT, 2000. 1Cd-Rom. (IPT, Publicação, 2651).

GOLOVANEVSKIY, V.A., BEARMAN, R.A. Gouging abrasion test for rock abrasiveness testing. International Journal of Mineral Processing, v.85, p.111-120, 2008.

INNAURATO, N., MANCINI, R. Forecasting the rock abrasivity in the civil and mining technological fields. In: INTERNATIONAL SCOCIETY OF THE ROCK MECHANICS REGIONAL SYMPOSIUM PREDICTION AND PERFORMANCE IN ROCK MECHANICS AND ROCK ENGINEERING, EUROCK'96, 1996, Torino. Proceedings... Rotterdam: Balkema, 1996. v.2, p.699-706.

WEST, G. A review of rock abrasiveness for tunneling. In: INTERNATIONAL SYMPOSIUM ON WEAK ROCK, Tokyo, 1981. Proceedings... Rotterdam: Balkema, 1982. v. 3, p.585-594.

WEST, G. Technical note: rock abrasiveness testing for tunneling. International Journal of Rock Mechanics and Mining Science \& Geomechanics Abstract, v.26, n.2, p.151-160, 1989.

Artigo recebido em 24 de junho de 2010. Aprovado em 22 de abril de 2013. 